\title{
THE EFFECT OF PIOGLITAZONE ON GENOMIC INSTABILITY IN INDUCED DIABETIC RATS
}

\author{
KARAM A. AMEIN, Ph.D.**; MOUSTAFA M. HAMDY, M.D.*; RANIA A. ABD EL-EMAM, M.Sc.* and FIKRY H. \\ OSMAN, M.D.*
}

The Department of Pharmacology, Faculty of Medicine* and The Department of Genetics, Faculty of Agriculture**, Assiut University

Corresponding author: Karam Abd El-Naeem Amein

Address: Department of Genetics, Faculty of Agriculture, Assiut University, Assiut, Egypt.

Mobile number: 00201005602074 E-mail: karamamein@yahoo.com

\begin{abstract}
Thiazolidinediones (TZDs) include a group of antihyperglycemic agents that enhance insulin sensitivity and reduce insulin resistance at sites of insulin action specifically skeletal muscles, liver and adipose tissue. In September 2010, the FDA has launched a safety review of pioglitazone citing preliminary epidemiologic evidence suggesting that pioglitazone may be linked to a higher risk for bladder cancer. Bladder tumors were seen in male rats receiving a clinical dose of pioglitazone. Also, in 2 clinical studies, patients receiving pioglitazone experienced a higher rate of bladder cancer than patients taking other agents (Lewis et al., 2008). In this study, the genotoxic and cytotoxic potential of pioglitazone $(20,40$ and $80 \mathrm{mg} / \mathrm{kg}$, orally daily for 4 weeks) was evaluated against the nicotinamide $(230 \mathrm{mg} / \mathrm{kg}$ ) and streptozotocin $(65 \mathrm{mg} / \mathrm{kg})$ induced somatic and germinal cells defect using a battery of in vivo cytogenetic assays such as the micronucleus, chromosome aberration, mitotic index and sperm abnormality test in male Wistar rats. The obtained results demonstrated that pioglitazone significantly reduced the diabetes-induced genetic damage in both somatic and germinal cells and improved the cell proliferation changes in somatic cells which was attributed to its antioxidant properties. A significant elevation, however, in polyploidy was noticed in the diabetic rats treated with $80 \mathrm{mg} / \mathrm{kg}$ of pioglitazone. As numerical chromosomal aberrations have also been associated with tumorigenesis, this observation suggests a possible genotoxic effect of pioglitazone when used for a long period in treating diabetes.
\end{abstract}

Keywords: Diabetes, Pioglitazone, Chromosomal aberrations, Micronuclei, Carcinogenicity, sperm abnormalities.

\section{INTRODUCTION}

Diabetes mellitus (DM) is a serious and growing health problem worldwide and is associated with severe acute and chronic complications. Both diabetes and cancer are prevalent diseases whose incidence is increasing globally (Vigneri et al., 2009). The association between cancer and diabetes has been investigated extensively and most, but not all studies, found that DM is associated with an increased risk of several types of cancer (Vigneri et al., 2009).

Oxidative stress can be associated with type II DM and reactive oxygen species produced during this stress may cause DNA damage (Poulsen, 2005). Moreover, individuals with DM have reduced antioxidant defense capacity (Nuttal et al., 1999).
It has been reported that DNA damage and repair play a major role in neoplastic transformation, because mutations in DNA repair genes (e.g. BRCA1 and BRCA2) can be directly related with cancer and the efficacy of DNA repair may determine the susceptibility to carcinogenesis (Cousineau et al., 2005). The oxidative damage to the germinal cells is considered to be the leading cause for infertility and other congenital and developmental defects (Singh et al., 2004). This oxidative DNA damage and the decreased efficacy of DNA repair can contribute to the genetic damage in diabetics and, in consequence, to cancer (Powell et al., 2005). Thiazolidindiones belong to the class of drugs known as insulin sensitizers. They enhance insulin sensitivity by increasing the efficiency of glucose transporters 
and reducing both fasting and postprandial glucose concentrations. Thiazolidindiones activate peroxisome proliferator activated $\gamma$ (PPAR $\gamma$ ) nuclear receptors throughout the body, exerting their main insulin-sensitization in fat and muscles (Fonseca and Kulkarni, 2008). Beyond the metabolic actions, several studies indicate that TZDs may have anticancer properties in a variety of different epithelial malignancies (Blanquicett et al., 2008). In vitro studies indicate that PPAR $\gamma$ agonists have several anticancer activities, such as inhibiting growth and inducing apoptosis and cell differentiation (Ohta et al., 2001), and PPAR $\gamma$ is currently considered a potential target for both chemoprevention and cancer therapy (Panigrahy et al., 2005 and Ondrey, 2009). However, data on these insulin-sensitizing drugs (thiazolidinediones) are still controversial because other studies suggest that TZDs can potentiate tumorigenesis, and they have been considered by some to be multi-species, multi-sex carcinogens (Rubenstrunk et al., 2007). Studies in colon and breast carcinogenesis have shown that TZDs dependent activation of PPAR $\gamma$ leads to an increase of tumor formation (Saez et al., 1998 and Saez et al., 2004). Urothelial tumors in rats, particularly in the urinary bladder, have become an increasing concern with respect to predicting possible human cancer risk for PPAR $\gamma$ agonists (El-Hage, 2005). Therefore, the effect of TZDs on the risk of cancer or cancer progression in humans is still unclear (Rubenstrunk et al., 2007). Among the battery of tests available, micronucleus test, chromosomal aberrations, mitotic activity and sperm abnormality assays are commonly employed to evaluate the drug/disease induced mutations (Chauhan et al., 2000).

The present study aimed at exploring the likelihood of development of genetic damage in somatic and germinal cells in type 2 diabetic rat models following the administration of pioglitazone. A battery of in vivo cytogenetic assays, through several endpoints such as induction of micronuclei, chromosome aberrations and mitotic activity of bone marrow cells as well as evaluation of the effect of pioglitazone administration on sperm count and sperm shape abnormalities have been carried out.

\section{MATERIALS AND METHODS}

\section{Drugs and Chemicals}

Streptozotocin was purchased from MP Biomedicals, LLC., France while nicotinamide was purchased from Alpha Chem., India. Pioglitazone was supplied as a gift from Medical Union Pharmaceuticals CO., S.A.E. Staining reagents and other chemicals used in this study were of analytical grade and procured from Loba Chemie PVT. LTD. Mumbai, India and EI Nasr Pharmaceutical chemical CO., Egypt.

\section{Experimental Animals}

This study was conducted on adult male Wistar albino rats. Animals were obtained from the animal house of Faculty of Medicine, Assuit University. Their weight ranged between 180-250 grams and their age ranged between 12-14 weeks. Rats were housed in groups in clean capacious cages under standard laboratory conditions including good aerated room with suitable temperature $(25 \pm 5$ 으), maintained at good light. They were fed with standard rodent food and had free access to water.

\section{Experimental Design}

In the present study, rats were divided into the following groups; each consisting of 6 rats.

Group I: Control non-diabetic rats.

Group II: Control diabetic rats, non-treated.

Group III: Diabetic rats treated with pioglitazone, orally in a dose of $20 \mathrm{mg} / \mathrm{kg}$ body weight daily for four weeks.

Group IV: Diabetic rats treated with pioglitazone, orally in a dose of $40 \mathrm{mg} / \mathrm{kg}$ body weight daily for four weeks.

Group V: Diabetic rats treated with pioglitazone, orally in a dose of $80 \mathrm{mg} / \mathrm{kg}$ body weight daily for four weeks.

Sampling was done 24 hours after the last dose. The doses of pioglitazone were selected as previous reports (Bedir et al., 2008).

\section{Experimental Induction of Diabetes}

Type 2 diabetes was induced by combination of streptozotocin (STZ) and nicotinamide (NAD) in adult rats. The rats administered NAD $(230 \mathrm{mg} / \mathrm{kg}$, I.P.) dissolved in saline $15 \mathrm{~min}$ before STZ (65 mg/kg, I.P.) to develop moderate and stable hyperglycemia. Streptozotocin was freshly dissolved in sterile $0.9 \%$ saline solution. The control non-diabetic rats were injected with an equal volume of sterile $0.9 \%$ saline solution. Blood glucose level was determined 72 hours after STZ injection by FreeStyle Freedom ${ }^{\circledR}$ Lite glucometer. The diabetic rats included in the study 
had blood glucose level > $200 \mathrm{mg} / \mathrm{dl}$ (Rabbani et al., 2009).

Treatment with pioglitazone was started on the fourth day after STZ injection (i.e., after the estimation of blood glucose).

Experimental procedures:

Cytogenetic assays:

\section{Micronucleus assay (MN)}

The bone marrow MN assay was performed as the method described by Attia and his colleagues 2009. Rats were sacrificed under light ether anesthesia at the specified time after treatment with pioglitazone and both femurs were dissected out. The epiphyses were cut off and the bone marrow cells were flushed out in conical centrifuge tubes using $1 \mathrm{cc}$ syringe containing hypotonic $(0.56 \%)$ potassium chloride solution. The cells were allowed to stand in the hypotonic solution for 15 minutes at room temperature (or $37^{\circ} \mathrm{C}$ if room is cool). The suspension was then centrifuged at $400 \mathrm{rpm}$ for 5 minutes and the pellet was carefully suspended in $2 \mathrm{ml}$ of freshly prepared fixative (methanol:glacial acetic acid, 3:1). The cells were allowed to stand in it for 30 minutes at room temperature (or 37으 if room was cool). Centrifugation was done again at $400 \mathrm{rpm}$ for 5 minutes. Supernatant was discarded and another 2 $\mathrm{ml}$ of fresh fixative was added. The process of centrifugation was repeated twice more before slide preparation (Attia et al., 2009).

\section{Slide preparation:}

Two smears of bone marrow were prepared from each rat. Slides were prepared by putting few drops of fixed cells on dry, clean, grease-free slides and were allowed to dry in air. After air drying, the smears were coded and stained by $5 \%$ Giemsa stain [stock Geimsa stain/ distilled water] for 15 minutes. From each animal, 1000 polychromatic erythrocytes (PCEs) were examined for micronucleated erythrocytes (MNEs) under 1000x magnification using an Olympus microscope (Attia et al., 2009).

\section{Metaphase Chromosome aberrations assay}

At the specified time after treatment, groups of rats were intraperitonially injected with colchicine (0.5\%) at $4 \mathrm{mg} / \mathrm{kg} 90 \mathrm{~min}$ before sacrifice (Attia et al., 2009). The slides for chromosome analysis were prepared and stained as described earlier in the micronucleus assay. All slides were coded and scored under 1000x magnification using an Olympus microscope. Fifty well- spread metaphase plates per rat were scored for both structural aberrations and polyploidy in bone marrow cells [300 metaphases for each group].
Cells were classified according to the most severe damage which had occurred and were placed in only one of four categories:

1- Cells with DNA break (e.g. chromosomal breaks and chromatid breaks).

2- Acentric fragments.

3- Centric rings (i.e. ring chromosomes).

4- Polyploidy (i.e. cells contain multiples of the haploid chromosome number $(n)$ other than the diploid number (i.e., $3 n, 4 n$ and so on).

Evaluation of the mitotic activity of bone marrow cells by estimation of the mitotic index (MI)

From the same slides of metaphase chromosome aberration assay, 1000 cells from each animal were taken into consideration for the mitotic activity study, mitotic index. The mitotic index of bone marrow was evaluated by calculating the number of dividing cells in a population of 1000 cells (Attia et al., 2009).

\section{Cauda epididymal spermatozoa evaluation:}

For sperm characteristic analysis, the epididymal content of each rat was collected to estimate the frequencies of sperm count and sperm shape abnormalities. Immediately after scarification, both caudae epididymes of each animal were dissected and incisions were made. Then they were placed individually into tubes filled with $3 \mathrm{ml}$ of phosphate buffer saline. The tubes were placed in an incubator at $32 \circ \mathrm{C}$ for $30 \mathrm{~min}$ to allow the sperm to actively leave the epididymes. The slides were examined by bright field microscope with an oil immersion lens according to published protocol (Wyrobek and Bruce, 1975). Two hundred sperms per group were scored and the abnormalities were categorized as close as to those described by Wyrobek and Bruce, (1975). Abnormal sperms had forms readily recognizable as amorphous, without hook, headless tails, triangular and tail abnormality. Sperm count was determined under the microscope using a Neubauer hematocytometer according to the World Health Organization manual for the examination of human semen and two counts per animal were averaged (World Health Organization, 1992).

\section{Blood glucose estimation}

Fasting blood glucose estimation was done using the glucometer (Freestyle Freedom ${ }^{\circledR}$ Lite glucometer, TheraSense, Inc., U.S.A.). Blood sampling was done via the tail incision method. A drop of blood collected from the tail vein was gently applied over the test zone of the glucometer 
and the blood glucose level was recorded immediately as $\mathrm{mg} / \mathrm{dL}$.

Data analysis:

Statistical analysis was done using the computer software Graphpad Prism 5.0. Data were expressed as the mean \pm standard error (SE) of the means for each group. The frequency of chromosomal aberration was computed as the number of aberration per total metaphases at each group. When two groups were compared, unpaired $t$-test was used. The difference was insignificant at $p$ value $>0.05$, significant at $p$-value $<0.05$. The results of the assessed parameters in different treatment groups were compared with the diabetic untreated control group and the non-diabetic control group by one way analysis of variance (ANOVA). Analyses revealing $p$-values $<0.05$ were deemed to be statistically significant.
Effect of 4 weeks exposure with pioglitazone on the frequency of bone marrow micronuclei in NA-STZ induced diabetic rats:

The results of the micronucleus assay are presented in Table 1. Significant increases in the frequency of MNEs were observed in all diabetic rats in comparison with the control non-diabetic rats $[p<0.05$ (unpaired $t$-test)]. Diabetic animals treated with $20 \mathrm{mg} / \mathrm{kg}$ of pioglitazone showed a significant reduction in the frequency of MNEs in comparison with the diabetic control group $[p<$ 0.05 (one-way ANOVA followed by Dunnett test for multiple comparisons)]. A significant reduction was also observed in the diabetic animals treated with both 40 and $80 \mathrm{mg} / \mathrm{kg}$ of pioglitazone in comparison with the control groups [ $p<0.05$ (oneway ANOVA followed by Dunnett test for multiple comparisons)].

\section{RESULTS AND DISCUSSION}

Table 1: Frequencies of micronucleated polychromatic erythrocytes (MNPCEs) in bone marrow of non-diabetic and diabetic rats $24 \mathrm{~h}$ after the last treatment with the indicated doses of pioglitazone. Frequencies expressed as mean $\pm \mathrm{SE}$ for 6 observations.

\begin{tabular}{lc}
\hline Groups and chemicals (mg/kg) & $\begin{array}{c}\text { MN frequencies after 4 weeks of } \\
\text { exposure } \\
\text { (mean } \pm \text { SE) }\end{array}$ \\
\hline Non-diabetic control & $2.1 \pm 0.3$ \\
NA-STZ diabetic control (CMC) & $4.1 \pm 0.30^{*}$ \\
Diabetic+Pioglitazone (20) & $2.6 \pm 0.21^{\mathrm{b}}$ \\
Diabetic+Pioglitazone (40) & $1.6 \pm 0.21^{\mathrm{b}}$ \\
Diabetic+Pioglitazone (80) & $1.0 \pm 0.44^{\mathrm{b}}$ \\
\hline
\end{tabular}

* $\quad p<0.05$ vs non-diabetic control (unpaired $t$-test). ${ }^{\mathrm{a}} p<0.05$ vs non-diabetic control, ${ }^{\mathrm{b}} \quad p<0.05 v s$ diabetic control (one-way ANOVA followed by Dunnett test for multiple comparisons).

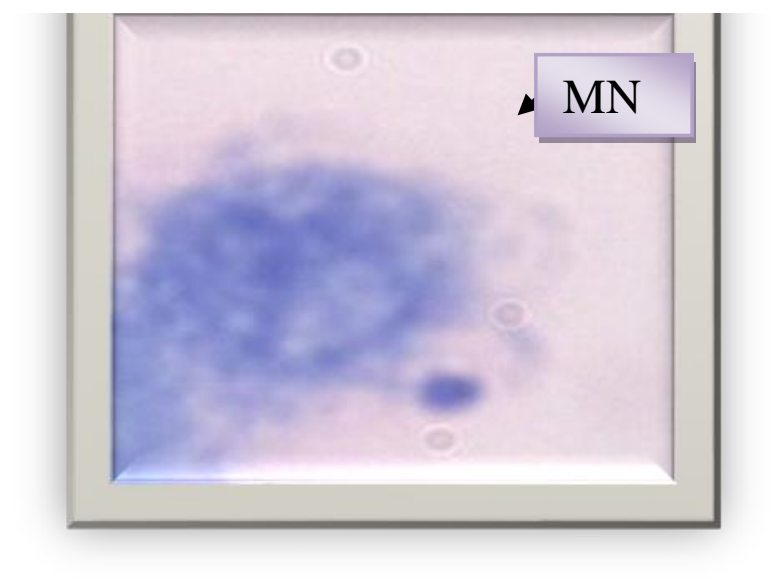

$\mathrm{MN}=$ Micronuclei

Fig 1: Microscopic image of bone marrow at interphase stage showing MNPCE. 
Effect of 4 weeks exposure with pioglitazone on the frequency of structural chromosomal aberrations in NA-STZ induced diabetic rats:

The results of the structural chromosomal aberrations (CAs) are presented in Table 2 . Significant increase in the frequency of total chromosomal aberrations was observed during the diabetic phase [ $p<0.05$ (unpaired $t$-test)]. Cells with chromosomal breaks were observed frequently in the diabetic rats and were statistically significant in comparison with the non-diabetic control group [ $p<0.05$ (unpaired $t$-test)].

Table 2: Frequencies of different types of structural chromosomal aberrations and mitotic index in bone marrow of non-diabetic and diabetic rats $24 \mathrm{~h}$ after the last treatment with the indicated doses of pioglitazone. Frequencies expressed as mean \pm SE for 6 observations.

\begin{tabular}{|c|c|c|c|c|c|}
\hline \multicolumn{6}{|c|}{ Types of structural chromosomal aberrations (Mean \pm SE) } \\
\hline $\begin{array}{l}\text { Groups and chemicals } \\
\qquad(\mathrm{mg} / \mathrm{kg})\end{array}$ & Breaks & Acenteric & Ring & TotalCAs & $\mathrm{MI}$ \\
\hline $\begin{array}{l}\text { Non-diabetic control } \\
\text { (4 weeks) }\end{array}$ & $0.6 \pm 0.3$ & $0.3 \pm 0.2$ & $1.0 \pm 0.3$ & $2.0 \pm 0.4$ & $13.8 \pm 1.3$ \\
\hline $\begin{array}{l}\text { NA-STZ diabetic control } \\
\text { (4 weeks exposure) }\end{array}$ & $2.0 \pm 0.25^{*}$ & $0.3 \pm 0.2$ & $1.0 \pm 0.3$ & $3.6 \pm 0.42^{*}$ & $2.8 \pm 0.3^{*}$ \\
\hline $\begin{array}{c}\text { Diabetic+Pioglitazone } \\
\text { (20) }\end{array}$ & $0.83 \pm 0.3^{b}$ & $0.3 \pm 0.2$ & $0.0 \pm 0.0^{\mathrm{ab}}$ & $1.0 \pm 0.36^{b}$ & $3.3 \pm 0.21^{\mathrm{a}}$ \\
\hline Diabetic+Pioglitazone (40) & $0.66 \pm 0.21^{b}$ & $0.16 \pm 0.1$ & $0.3 \pm 0.2$ & $0.83 \pm 0.3^{b}$ & $7.0 \pm 0.25^{\mathrm{ab}}$ \\
\hline \multicolumn{6}{|l|}{ Diabetic+Pioglitazone (80) } \\
\hline & $0.5 \pm 0.22^{b}$ & $0.16 \pm 0.1$ & $0.3 \pm 0.21$ & $0.33 \pm 0.21^{\mathrm{ab}}$ & $7.6 \pm 0.49^{\mathrm{ab}}$ \\
\hline
\end{tabular}

* $p<0.05$ vs non-diabetic control (unpaired t-test). ${ }^{\mathrm{a}} p<0.05$ vs non-diabetic control, ${ }^{\mathrm{b}} p<0.05$ vs diabetic control (one-way ANOVA followed by Dunnett test for multiple comparisons).
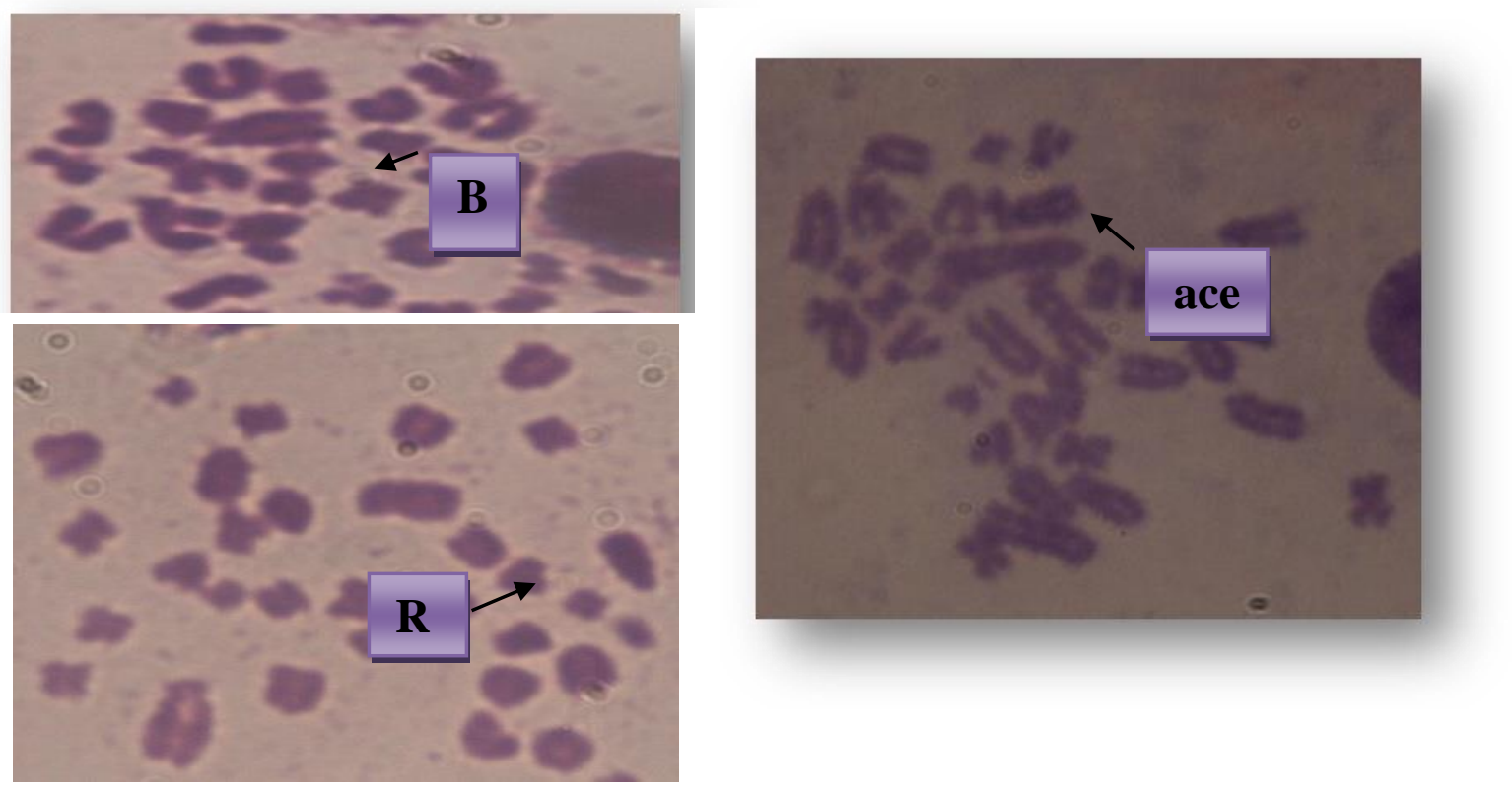

Figure 2 Microscopic images of bone marrow at metaphase stage showing chromatid breaks (B), acentric (ace) and ring (R) chromosomes. ). Original magnification x100. 
Treatment with $20 \mathrm{mg} / \mathrm{kg}$ of pioglitazone showed a significant decrease in the frequency of total chromosomal aberrations when compared to the diabetic control group [ $p<0.05$ (one-way ANOVA followed by Dunnett test for multiple comparisons). Cells with chromosomal breaks were also observed in the rats treated with the previous low dose of pioglitazone and were statistically significantly lower in comparison with the diabetic control group [ $p<0.05$ (one-way ANOVA followed by Dunnett test for multiple comparisons). Ring chromosomes were statistically lower in comparison with the diabetic control group $[p<$ 0.05 (one-way ANOVA followed by Dunnett test for multiple comparisons). Cells with chromosomal breaks and total chromosomal aberrations were statistically significantly lower in comparison with the diabetic control group [ $p<0.05$ (one-way ANOVA followed by Dunnett test for multiple comparisons)] in the diabetic animals treated with 40 and $80 \mathrm{mg} / \mathrm{kg}$ of pioglitazone.

\section{Effect of 4 weeks exposure with pioglitazone on the induced mitotic arrest in NA-STZ induced diabetic rats:}

Mitotic index data recorded in the bone marrow cells at metaphase stage are also presented in Table 2. Drastic inhibition in the mitotic activity of bone marrow cells was recorded in all diabetic rats when bone marrow cells were sampled during the diabetic phase [ $p<0.05$ (unpaired $t$-test)] when compared with the non-diabetic control group. The mitotic activity of bone marrow cells was elevated in diabetic rats treated with $20 \mathrm{mg} / \mathrm{kg}$ pioglitazone but was statistically insignificant when compared with the diabetic control group [ $p>0.05$ (one-way ANOVA followed by Dunnett test for multiple comparisons). In the diabetic groups treated with 40 and $80 \mathrm{mg} / \mathrm{kg}$ of pioglitazone the mitotic indices were significantly elevated in comparison with the diabetic control group [ $p<0.05$ (one-way ANOVA followed by Dunnett test for multiple comparisons).

Table 3: Frequencies of polyploidy in bone marrow cells of non-diabetic and diabetic rats $24 \mathrm{~h}$ after the last treatment with the indicated doses of pioglitazone. Frequencies expressed as mean \pm SE for 6 observations.

\begin{tabular}{lc}
\hline Groups and chemicals $(\mathrm{mg} / \mathrm{kg})$ & $\begin{array}{c}\text { Polyploidy }(3 \mathrm{n}) \text { frequencies after } 4 \text { weeks } \\
\text { of exposure } \\
\text { (mean } \pm \mathrm{SE})\end{array}$ \\
\hline Non-diabetic control & $0.2 \pm 0.01$ \\
NA-STZ diabetic control(CMC) & $0.54 \pm 0.02^{*}$ \\
Diabetic+Pioglitazone (20) & $0.5 \pm 0.01^{\mathrm{a}}$ \\
Diabetic+Pioglitazone (40) & $0.56 \pm 0.01^{\mathrm{a}}$ \\
Diabetic+Pioglitazone (80) & $0.69 \pm 0.03^{\mathrm{ab}}$ \\
\hline
\end{tabular}

* $p<0.05$ vs non-diabetic control (unpaired $t$-test). ${ }^{\mathrm{a}} p<0.05$ vs non-diabetic control, ${ }^{\mathrm{b}} p<0.05$ vs diabetic control (one-way ANOVA followed by Dunnett test for multiple comparisons).

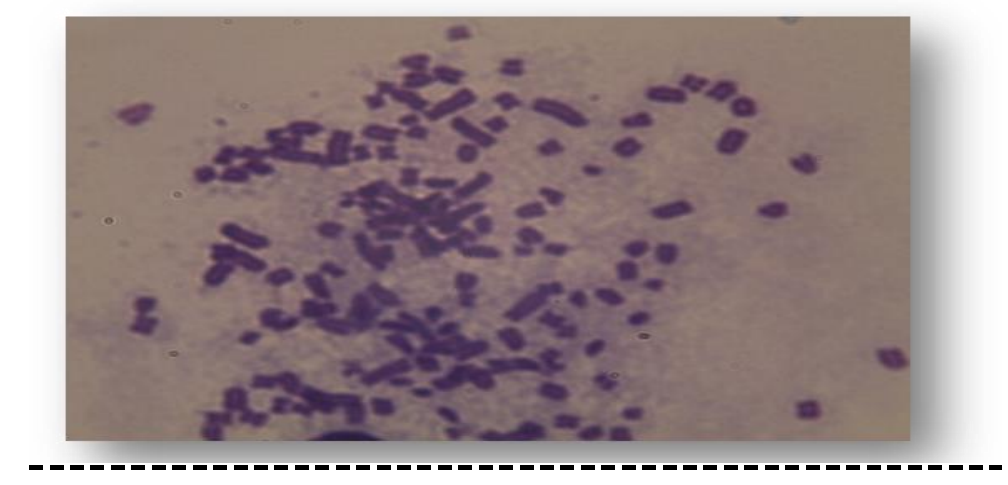

Fig. 3 Metaphase spreads from bone marrow of rat treated with $80 \mathrm{mg} / \mathrm{kg}$ pioglitazone showing polyploidy as a numerical chromosomal aberration. Original magnification x100. 
Effect of 4 weeks exposure with pioglitazone on the frequency of polyploidy in NA-STZ induced diabetic rats.

The results of polyploidy are presented in Table 3 . Significant increase in the frequency of polyploidy was observed during the diabetic phase $[p<0.05$ (unpaired $t$-test)] when compared with the nondiabetic control group. Diabetic animals treated with $20 \mathrm{mg} / \mathrm{kg}$ of pioglitazone showed a nonsignificant reduction in the frequency of polyploidy when compared to the diabetic control group [ $p>$ 0.05 (one-way ANOVA followed by Dunnett test for multiple comparisons)]. Treatment of diabetic animals with $40 \mathrm{mg} / \mathrm{kg}$ of pioglitazone showed a non-significant elevation in the frequencies of polyploidy in comparison with the diabetic control group [ $p>0.05$ (one-way ANOVA followed by Dunnett test for multiple comparisons). Treatment of diabetic animals with $80 \mathrm{mg} / \mathrm{kg}$ of pioglitazone showed a significant elevation in the frequencies of polyploidy in comparison with the diabetic control group [ $p<0.05$ (one-way ANOVA followed by Dunnett test for multiple comparisons).
Effect of 4 weeks exposure with pioglitazone on the frequency of sperm count and sperm morphology in NA-STZ induced diabetic rats:

The results of sperm count and sperm shape abnormalities are presented in Table 4 . Administration of NA-STZ significantly increased the occurrence of sperm shape abnormalities and reduced the sperm count compared to the control non-diabetic animals [ $p<0.05$ (unpaired $t$-test)]. Administration of $20 \mathrm{mg} / \mathrm{kg}$ of pioglitazone significantly reduced the sperm shape abnormalities $[p<0.05]$ while the sperm count was insignificantly elevated in comparison with diabetic control group [ $p>0.05$ ] (one-way ANOVA followed by Dunnett test for multiple comparisons)]. Administration of 40 and $80 \mathrm{mg} / \mathrm{kg}$ of pioglitazone significantly reduced sperm shape abnormalities and elevated sperm count in comparison with diabetic control group [ $p<0.05$ (one-way ANOVA followed by Dunnett test for multiple comparisons).

Table 4Frequencies of sperm count and sperm shape abnormalities of non-diabetic and diabetic rats $24 \mathrm{~h}$ after the last treatment with the indicated doses of pioglitazone. Frequencies expressed as mean \pm SE for 6 observations.

\begin{tabular}{|c|c|c|}
\hline Groups and chemicals (mg/kg) & $\begin{array}{c}\text { Sperm count after } \\
4 \text { weeks of } \\
\text { exposure } \\
\left(\times 10^{6} / \text { cauda }\right. \\
\text { epididymis }) \\
\text { (mean } \pm \mathrm{SE})\end{array}$ & $\begin{array}{c}\text { Total sperm shape } \\
\text { abnormality after } 4 \\
\text { weeks of exposure } \\
\text { (mean } \pm \text { SE) }\end{array}$ \\
\hline Non-diabetic control & $75.8 \pm 2.7$ & $1.0 \pm 0.5$ \\
\hline NA-STZ diabetic control(CMC) & $39.8 \pm 2.6^{*}$ & $13.6 \pm 1.11^{*}$ \\
\hline Diabetic+Pioglitazone (20) & $46.6 \pm 2.7^{a}$ & $9.16 \pm 0.6^{\mathrm{ab}}$ \\
\hline Diabetic+Pioglitazone (40) & $50.0 \pm 1.2^{\mathrm{ab}}$ & $7.16 \pm 0.4^{\mathrm{ab}}$ \\
\hline Diabetic+Pioglitazone (80) & $53.3 \pm 1.02^{\mathrm{ab}}$ & $5.5 \pm 0.22^{\mathrm{ab}}$ \\
\hline
\end{tabular}

${ }^{*} p<0.05$ vs non-diabetic control (unpaired $t$-test). ${ }^{a} p<0.05$ vs non-diabetic control, ${ }^{b} p<0.05 v s$ diabetic control (one-way ANOVA followed by Dunnett test for multiple comparisons). 


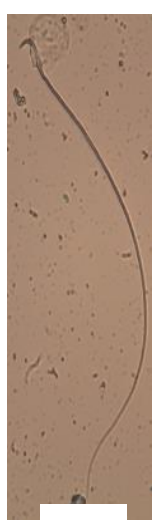

1

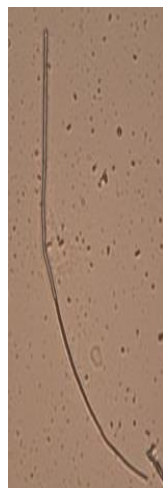

2

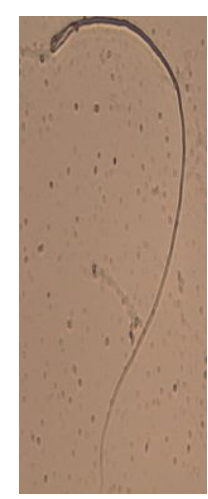

3

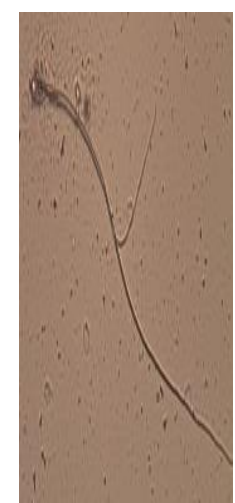

4

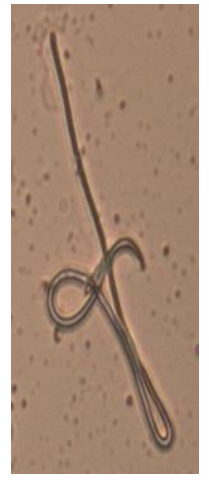

5

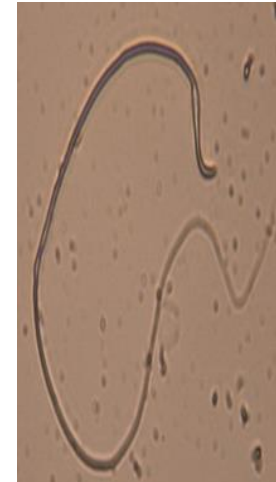

6

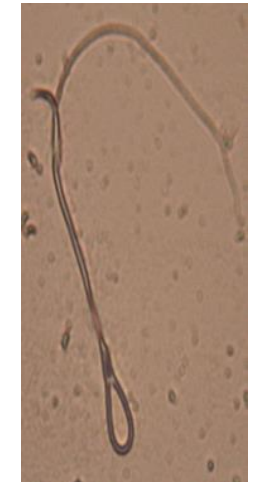

7

Fig. 3 Microscopic images of epididymal sperm showing normal sperm (1), headless (2), hookless (3), amorphous (4) and abnormal tails (5-7).

\section{DISCUSSION}

Diabetes mellitus itself is not responsible for a high mortality and morbidity among diabetic patients. They are caused mainly by its complications, first of all coronary heart disease, which are consequences of oxidative stress associated with diabetes (Nuttal et al., 1999; Clark, 2002). Some reports suggest also that diabetes can be associated with cancer, but the mechanism underlying this association is unclear (Lindbland et al., 1999). A previous study demonstrated that type II diabetes mellitus was linked with an elevated level of oxidative DNA damage, the increased susceptibility to mutagens and the decreased efficacy of DNA repairing enzymes (Blasiak et al., 2004). Oxidative DNA damage may contribute to cancer promotion and progression, therefore, it can be considered as an element of the link between diabetes and cancer (Evans and Cooke, 2004).

This study was conducted using a group of in vivo cytogenetic assays for evaluation of the possible genotoxic and cytotoxic potential of insulin glargine in diabetic rats, through several endpoints using the rat bone marrow. These are effective and sensitive short-term in vivo bioassays that utilize cytological damage as an end-point in detecting and screening chemical agents that induce chromosomal damages and rearrangement in vivo (Sanchez et al., 1988). In vivo cytogenetic methods are preferred to in vitro tests because of metabolic activation and detoxification of compounds that occur in the intact animals (Natarajan et al., 1976; Evans, 1977).
The diabetogenic agent STZ is a potent alkylating agent known to directly methylate DNA with subsequent induction of DNA strand breaks, chromosomal aberrations and DNA damage in mammalian cells in vitro (Weiss, 1982; Bolzan and Bianchi, 2002; Blasiak et al., 2004). Streptozotocin is also demonstrated to be carcinogenic in rats, mice and hamsters (Weiss, 1982).

Certain in vivo genotoxicity studies have shown that STZ significantly elevated the $M N$ in the mouse bone marrow cells (Liegibel et al., 1992; Chinnaswamy et al., 1998). In addition, an in vivo study carried out by Vikram et al. (2007) showed a marked increase in the MN and DNA damage in the bone marrow cells of rats treated with STZ. Moreover, the study conducted by Attia et al. (2009) showed a significant increase in the frequency of $\mathrm{MN}$, total chromosomal aberration and reduction in mitotic indices in the rats treated with STZ.

In agreement with the above-cited reports, the present study showed that exposure to STZ caused significant increase in the $\mathrm{MN}$ frequencies, total chromosomal aberration and reduction in mitotic indices as compared to the values obtained with control non-diabetic. The genetic damage observed in the rats with experimental diabetes, could be explained by many physiological changes caused by the pancreatic $\beta$-cell destruction induced by streptozotocin. This damage may trigger inflammatory processes, as well as hyperglycemia-induced oxidative stress, that may be sufficient to increase the genetic damage (Davi et al., 2005). Oxidative stress is associated with increased free radical production and as a 
consequence, with increased genetic damage (Ramos-Remus et al., 2002; Batista-Gonzalez et al., 2006).

The data of the present study demonstrated that administration of pioglitazone at a dose of 20, 40 and $80 \mathrm{mg} / \mathrm{kg}$ daily for four weeks reduced the frequencies of MNEs, total chromosomal aberrations (structural) and enhanced the mitotic indices. The administered doses also increased the sperm count and reduced the sperm shape abnormalities in hyperglycemic rats. The antioxidant profile indicated that the investigated drug elevated the plasma levels of total antioxidant enzymes and reduced the serum levels of MDA. These results are supported by the findings of Rabbani et al. (2008) which showed that administration of pioglitazone at doses of 1, 10 and $100 \mathrm{mg} / \mathrm{kg}$ for four weeks exhibited a significant suppression of micronuclei formation, reduction in the total number of sperm abnormality and elevation in sperm count. Moreover, Rabbani et al. (2010) showed that oral administration of pioglitazone at doses of 1 and $10 \mathrm{mg} / \mathrm{kg}$ for four weeks reduced the sperm shape abnormalities and increased the sperm counts besides decreasing the LPO and enhancing the reduced glutathione and GPx levels in the diabetic rats.

Lipid peroxidation occurs when ROS attack the polyunsaturated fatty acid residues of phospholipids of the cell membrane, which is extremely sensitive to oxidation. Spermatozoa are highly susceptible to damage by excess concentrations of ROS due to a high content of polyunsaturated fatty acid within their plasma membrane (Yagi, 1987 and Kumar et al., 2002).

The ability of pioglitazone to minimize the chromosomal damage in both somatic and germinal cells can be attributed to its antioxidant property since inhibition in the free radicals action is known to suppress the nuclear damage (Saiki et al., 2007). The antioxidant activity of pioglitazone has been extensively studied by other investigators. The study of Gumieniczek et al. (2008) indicated modulation of oxidative stress by pioglitazone in diabetic rabbits. In diabetic rabbits, an increase in the activity of antioxidative enzymes: SOD, CAT, GPX and glutathione reductase was observed. These effects were accompanied by a significant decrease in lipid oxidation. In addition, the study of Toblli et al.
(2009) showed that chronic administration of pioglitazone $12 \mathrm{mg} / \mathrm{kg}$ for four to five months led to the reduction of malonyldialdehyde production and the increase of the reduced glutathione/oxidized glutathione (GSH/GSSG) ratio levels in type 2 diabetic rats. Similarly, the study of Karabas and his colleagues (2013) indicated that oral administration of pioglitazone for four weeks into STZ-diabetic rats was able to reduce lipid peroxides and to increase the levels of CAT, SOD and reduced glutathione. Recently, attenuation of oxidative stress was observed in the skeletal muscles of type 2 diabetic mice treated with pioglitazone (Takada et al., 2014). The antioxidant activity of pioglitazone is reported to be mediated by blocking the vicious cycle of ROS production, improves insulin sensitivity and halts the proinflammatory signaling transduction (Hsiao et al., 2008).

An earlier study conducted by Bedir et al. (2008) to evaluate the genotoxic potential of pioglitazone indicated that the daily treatment of pioglitazone to rats has increased the percentage tail DNA damage in hepatocytes and lymphocytes. Enhancement in the oxidative stress due to generation of free radicals from the mitochondrial and/or extra mitochondrial sources was considered as the possible reason for the pioglitazone mediated nuclear damage (Bedir et al., 2008). Several studies in the past, however, have reported that TZDs posses potent antioxidant property. Both rosiglitazone and pioglitazone are known to exhibit an antioxidant effect against free radicals by enhancing the endogenous antioxidant enzyme defense (Gumieniczek, 2005; Bao et al., 2007 and Saiki et al., 2007). In vitro data demonstrate that multiple CYP isoforms are involved in the metabolism of pioglitazone. The isoforms involved are the hepatic CYP2C8, and, to a lesser degree, CYP3A4, with additional contributions from a variety of other isoforms including the extrahepatic metabolism of pioglitazone within the lymphocytes by CYP1A1 (Bedir et al., 2008). The ability of rosiglitazone and pioglitazone to induce the DNA damage in the liver cells could be because; TZDs are primarily metabolized in liver by CYP2C8 and CYP3A4 enzymes, the oxidative stress that occurs due to the metabolism might have produced the localized damage to the hepatocytes DNA (Bedir et al., 
2006). Meanwhile, the pioglitazone induced nuclear damage to the lymphocytes may be attributed to the extrahepatic metabolism of pioglitazone within the lymphocytes by CYP1A1 (Bedir et al., 2008).

A significant increase in polyploidy was observed in the diabetic animals treated with $80 \mathrm{mg} / \mathrm{kg}$ of pioglitazone for two and four weeks which was an interesting finding observed in the present study. Previous researches have shown that breast cancer susceptibility genes 1 and 2 (BRCA1/2) are known as tumor suppressor genes playing critical roles in DNA repair, cell cycle checkpoint control and in maintenance of the genomic stability. Both BRCA1 and BRCA2 suppress the cell cycle progression (Schuldt, 2001; Misra et al., 2010 and Shabbeer et al., 2012). Cancer cells in tissues of BRCA1 or BRCA2 mutation carriers are usually near tetraploidy and polyploidy (Jonsdottir et al., 2012 and $\mathrm{Yu}$ et al., 2012). In mammary epithelial cells, blocking BRCA1 function leads to the aberrant mitosis with binuclear and tetraploidy cells (Schlegel et al., 2003). Likewise, in murine embryo fibroblasts and cervical cancer cells, the absence of BRCA2 impairs the completion of cell division due to abnormal cytokinesis, leading to chromosomal polyploidization (Daniels et al., 2004). Yoshihara et al. (2012) found that common genes involved in cell cycle or cell proliferation were downregulated by pioglitazone treatment. These genes include G1/S or G2/M checkpoint related genes, breast cancer 2 and others. Therefore, the deprivation of BRCA1/2 would promote the abnormal cytokinesis and enhance the cell multinuclearity polyploidy and tetraploidy to modulate tumorigenesis (Wang et al., 2014).

On the light of all of these results, the authors of this study can conclude that pioglitazone possess a genotoxic effect when used for a long period in treating diabetes because numerical chromosomal aberrations have also been associated with tumorigenesis.

\section{Acknowledgements}

The authors acknowledge the financial support received from Assuit University. We are grateful for the Departments of Genetics and Pharmacology, Faculty of Medicine, Assuit University and every kind hand which helped and participated in accomplishment of this work.

\section{REFERENCES}

Attia SM, Helal GK, Alhaider AA (2009). Assessment of genomic instability in normal and diabetic rats treated with metformin. Chem. Biol. Interact. 180(2): 296-304.

Bao Y, Jia RH, Yuan J et al (2007). Rosiglitazone ameliorates diabetic nephropathy by inhibiting reactive oxygen species and its downstream signaling pathways. Pharmacol. 80(1):57-64.

Batista-Gonzalez CM, Corona-Rivera JR, GomezMeda BC, Zamora-Perez AL, Ramos-Ibarra ML, Zũniga-Gonzalez G (2006). Micronucleated erythrocytes in preterm newborns in relation to maternal pathology. Rev. Biomed. 17: 1116.

Bedir A, Aliyazicioglu Y, Kahraman H, Yurdakul Z, Uysal M, Suvaci DE, Okuyucu A, Ho“kelek M, Alvur M (2006). Genotoxicity in rats treated with the antidiabetic agent, Rosiglitazone. Environmental and Molecular Mutagenesis. 47: 718-724.

Bedir A, Yuksel A, Birsen B, Zafer Y, Mehmet U, Duygu ES, Ali O, Hakki K, Murat H, Muhlise A (2008). Assessment of Genotoxicity in Rats Treated With the Antidiabetic Agent, Pioglitazone. Environmental and Molecular Mutagenesis. 49: 185-191.

Blanquicett C, Roman J, Hart CM (2008). Thiazolidinediones as anti-cancer agents. Cancer Ther. 6(A): 25-34.

Blasiak J, Arabski M, Krupa R, Wozniak MZ, Kasznicki J, Zurawska M, Zurawska $M$, Drzewoski J (2004). DNA damage and repair in type 2 diabetes mellitus. Mutat. Res. 554: 297-304.

Bolzan AD, Bianchi MS (2002). Genotoxicity of streptozotocin. Mutat. Res. 7690: 1-14.

Chauhan LKS, Pant N, Gupta SK, Srivastava SV (2000). Induction of chromosome aberrations, micronucleus formation and sperm abnormalities in mouse following carbafuran exposure. Mutat. Res. 465: 123.

Chinnaswamy N, Fairbairn L, Laher J, Willington MA, Rafferty JA (1998). Modulation of O6alkylating agent induced clastogenecity by enhanced DNA repair capacity of bone marrow cells. Mutat. Res. 416: 1-10. 
Clark SF (2002). The biochemistry of antioxidants revisited. Nutr. Clin. Pract. 17: 5-17.

Cousineau I, Abaji C, Belmaaza A (2005). BRCA1 regulates RAD51 function in response to DNA damage and suppresses spontaneous sister chromatid replication slippage: implications for sister chromatid cohesion, genome stability, and carcinogenesis. Cancer Res. 15: 11384-11391.

Daniels MJ, Wang Y, Lee $M$, Venkitaraman AR (2004). Abnormal cytokinesis in cells deficient in the breast cancer susceptibility protein BRCA2. Science. 306:876-879.

Davi G, Falco A, Patrono C (2005). Lipid peroxidation in diabetes mellitus. Antioxid. Redox Signal. 7: 256-268.

El-Hage J (2005). Peroxisome proliferationactivated receptor agonists: Carcinogenicity findings and regulatory recommendations. International Atherosclerosis Society Symposium on PPAR, Monte Carlo.

Evans HJ (1977). Progress in Genetic Toxicology. Amsterdam, Elservier. (North Holland) 57-74.

Evans MD, Cooke MS (2004). Factors contributing to the outcome of oxidative damage to nucleic acids. Bioessays. 26: 533-542.

Fonseca VA, Kulkarni KD (2008). Management of type 2 diabetes: oral agents, insulin and injectables. J Am Diet 2Assoc. 108: S29-S33.

Gumieniczek A (2005). Effects of Pioglitazone on hyperglycemia induced alterations in antioxidative system in tissues of alloxan treated diabetic animals. Exp Toxicol Pathol. 56:321-326.

Gumieniczek A, Hopkała H, Zabek A (2008). Protective effects of a PPARgamma agonist pioglitazone on anti-oxidative system in testis of diabetic rabbits. Pharmazie. 63(5):377-378.

Hsiao PJ, Hsieh TJ, Kuo KK, Hung WW, Tsai KB et al (2008). Pioglitazone retrieves hepatic antioxidant DNA repair in a mice model of high fat diet. BMC Molecular Biology. 9: 82.

Jonsdottir AB, Stefansson $O A$, Bjornsson J, Jonasson JG, Ogmundsdottir HM, Eyfjord JE (2012). Tetraploidy in BRCA2 breast tumours. Eur J Cancer. 48:305-310.

Karabas M, Ayhan M, Guney E, Serter M, Meteoglu I (2013). The effect of pioglitazone on antioxidant levels and renal histopathology in streptozotocin-induced diabetic rats. ISRN Endocrinol 9:858690.

Kumar TR, Doreswamy K, Shrilatha B (2002). Oxidative Stress Associated DNA Damage in Testis of Mice: Induction of Abnormal Sperms and Effects on Fertility. Mutat Res. 513:103111.

Liegibel U, Tinwell H, Callander RD, Schmezer P, Ashby J (1992). Clastogenicity to the mouse bone marrow of the mouse germ cell genotoxin streptozotocin. Mutagenesis. 7: 471-474.

Lindblad P, Chow WH, Chan J, Bergstrom A, Wolk A, Gridley G, McLaughlin JK, Nyren O, Adami $\mathrm{HO}$ (1999). The role of diabetes mellitus in the aetiology of renal cell cancer. Diabetologia. 42: 107-112.

Misra S, Sharma S, Agarwal A, Khedkar SV, Tripathi MK, Mittal MK, Chaudhuri G (2010). Cell cycle-dependent regulation of the bidirectional overlapping promoter of human BRCA2/ZAR2 genes in breast cancer cells. Mol Cancer. 9:50.

Natarajan AT, Tates AD, Van Bull PPW, Meiyers M, de Vogil N (1976). Cytogenetic Effects of Mutagens/Carcinogens after Activation in a Microsomal System InVitro, I. Induction of Chromosome Aberrations and Sister Chromatid Exchanges by Diethylnitrosamine (DEN) and Dimethylnitrosamine (DMN) in $\mathrm{CHO}$ Cells in the Presence of Rat-Liver Microsomes. Mutat. Res. 37: 83-90.

Nuttal SL, Dunne F, Kendall MJ, Martin U (1999). Age-independent oxidative stress in elderly patients with non-insulin-dependent diabetes mellitus. QJM. 92: 33-38.

Ohta K, Endo T, Haraguchi K, Hershman JM, Onaya $T$ (2001). Ligands for peroxisome proliferatoractivated receptor gamma inhibit growth and induce apoptosis of human papillary thyroid carcinoma cells. J Clin Endocrinol Metab. 86:2170-2177.

Ondrey F (2009). Peroxisome proliferator-activated receptor gamma pathway targeting in carcinogenesis: implications for chemoprevention. Clin Cancer Res. 15:2-8.

Panigrahy D, Huang S, Kieran MW, Kaipainen A (2005). PPAR gamma as a therapeutic target for tumor angiogenesis and metastasis. Cancer Biol Ther. 4:687-693. 
Poulsen HE (2005). Oxidative DNA modifications. Exp. Toxicol. Pathol. 57(1): 161-169.

Powell CL, Swenberg JA, Rusyn I (2005). Expression of base excision DNA repair genes as a biomarker of oxidative DNA damage. Cancer Lett. 229: 1-11.

Rabbani SI, Devi K, Khanam S (2008). Effect of thiazolidinediones on the erythropoeitic and germinal cells in the male wistar rats. Clin Med Oncol. 2:423-429.

Rabbani SI, Devi K, Khanam S (2009). Inhibitory effect of glimepiride on nicotinamidestreptozotocin induced nuclear damages and sperm abnormality in diabetic Wistar rats. Indian J Exp Biol. 47(10): 804-810.

Rabbani SI, Devi K, Khanam S (2010). Pioglitazone, a PPAR-gamma ligand inhibited the nicotinamide-streptozotocin induced sperm abnormalities in type-2 diabetic Wistar rats. Pak J Pharm Sci. 23(3):326-331.

Ramos-Remus C, Dorazco-Barragan G, Aceves-Avila FJ, Alcaraz-Lopez F, Fuentes-Ramirez F, Michel-Diaz J, Torres-Bugarin O, VenturaAguilar A, Zũniga-Gonzalez G (2002). Genotoxicity assessment using micronuclei assay in rheumatoid arthritis patients. Clin. Exp. Rheumatol. 20: 208-212.

Rubenstrunk A, Hanf R, Hum DW, Fruchart JC, Staels B (2007). Safety issues and prospects for future generations of PPAR modulators. Biochim Biophys Acta. 1771:1065-1081.

Saez E, Tontonoz P, Nelson MC, Alvarez Ming UT, Baird SM, et al (1998). Activators of nuclear receptor PPAR $\gamma$ enhance colon polyp formation. Nat Med. 4:1058-1061.

Saez E, Rosenfeld J, Livolsi A, Olson P, Lombardo E, Nelson $M$, et al (2004). PPAR gamma signaling exacerbates mammary gland tumor development. Genes Dev. 18:528-540.

Saiki R, Okazaki M, Iwai S, et al (2007). Effect of Pioglitazone on increases in visceral fat accumulation and oxidative stress in spontaneously hypertensive hyperlipidemic rats fed a high fat diet and sucrose solution. J Pharmacol Sci. 105(2):156-167.

Sanchez PS, Sato M, Paschoal CMRB, Alives MN, Furlan EV, Martins MT (1988). Toxicity Assessment. B 55-80.

Schlegel BP, Starita LM, Parvin JD (2003). Overexpression of a protein fragment of RNA helicase $A$ causes inhibition of endogenous BRCA1 function and defects in ploidy and cytokinesis in mammary epithelial cells. Oncogene. 22:983-991.

Schuldt A (2001). Cell cycle. A complex twist for BRCA2. Nat Rev Mol Cell Biol. 2:164.

Shabbeer S, Omer D, Berneman D, Weitzman O, Alpaugh A, Pietraszkiewicz A, Metsuyanim S, Shainskaya A, Papa MZ, Yarden RI (2012). BRCA1 targets G2/M cell cycle proteins for ubiquitination and proteasomal degradation. Oncogene. 32:5005-5016.

Singh P, Jain A, Kaur G (2004). Impact of hypoglycemia and diabetes on CNS: correlation of mitochondrial oxidative stress with DNA damage. Mol. Cell. Biochem. 260: 153-159.

Takada S, Hirabayashi K, Kinugawa S, Yokota T, et al (2014). Pioglitazone ameliorates the lowered exercise capacity and impaired mitochondrial function of the skeletal muscle in type 2 diabetic mice. Eur J Pharmacol. 740:690-696.

Toblli E, Monica G, Gabriel C, Vernet D, Angerosa $M$, Nestor $F$ (2009). Antifibrotic effects of pioglitazone on the kidney in a rat model of type 2 diabetes mellitus. Nephrol Dial Transplant. 24: 2384-2391.

Vigneri P, Frasca F, Sciacca L, Pandini G, Vigneri R (2009). Diabetes and cancer. Endocr. Relat. Cancer. 16(4): 1103-1123.

Vikram A, Tripathi DN, Ramarao P, Jena GB (2007). Evaluation of streptozotocin genotoxicity in rats from different ages using the micronucleus assay. Regul. Toxicol. Pharmacol. 49: 238-244.

Wang Y, Wang Z, Qi Z, Yin S, Zhang N, Liu Y, Liu M, Meng J, Zang R, Zhang Z,Yang G (2014). The negative interplay between Aurora $A / B$ and BRCA1/2 controls cancer cell growth and tumorigenesis via distinct regulation of cell cycle progression, cytokinesis, and tetraploidy. Molecular Cancer. 13: 1-12.

Weiss RB (1982). Streptozotocin: a review of its pharmacology, efficacy and toxicity. Cancer Treat. Rep. 66: 427-438.

World Health Organisation (1992). WHO Laboratory Manual for the Examination of Human Semen Samples and Sperm-Cervical Mucus Interaction, 3rd ed., Press Syndicate of 
the University of Cambridge, Cambridge, UK. 23-27.

Wyrobek AJ, Bruce WR (1975). Chemical induction of sperm abnormalities in mice. Proc. Natl. Acad. Sci. 72: 4425-4429.

Yagi K (1987). Lipid Peroxides and Human Diseases. Chem Phys Lipids. 45: 337-351.

Yoshihara D, Kugita M, Yamaguchi T, Aukema HM, Kurahashi H, Morita M, Hiki Y, Calvet JP,
Wallace DP, Toyohara T, Abe T, Nagao S (2012). Global Gene Expression Profiling in PPAR- $\gamma$ Agonist-Treated Kidneys in an Orthologous Rat Model of Human Autosomal Recessive Polycystic Kidney Disease. PPAR Res. 2012:695898.

Yu VM, Marion CM, Austria TM, Yeh J, Schonthal $A H$, Dubeau L (2012). Role of BRCA1 in controlling mitotic arrest in ovarian cystadenoma cells. Int J Cancer. 130:24952504. 